\title{
Research on the Evolution Mechanism and Countermeasures of Green Building Market Based on Evolutionary Game Theory
}

\author{
Zhongfu Qin ${ }^{1, a}$, Jingping $\mathrm{Li}^{1, \mathrm{~b} *}$ and Zhongyang $X \mathrm{u}^{1, \mathrm{c}}$ \\ ${ }^{1}$ College of Civil Engineering and Architecture, Zhejiang University, Hangzhou, Zhejiang, China \\ aqinzhongfu@zju.edu.cn, blijingping980322@163.com, ${ }^{\text {c2 } 21412002 @ z j u . e d u . c n ~}$
}

Keywords: Green building market; Evolutionary game; Evolution mechanism; Replication dynamics; Development trend

\begin{abstract}
In order to study the evolution mechanism and forecast the development direction of green building market, this paper establishes a model of asymmetric evolutionary game in the green building market by using the idea of evolutionary game firstly. Then the dynamic equations of the two strategies are set up by using the idea of "replicator dynamics" in evolution game. Lastly the evolutionary game equilibrium model is established. The analysis results show that (build green, buy green),(build non green,buy non green) are the two evolutionary stable situations. Through the empirical analysis, the development of green building in our country is divided into three development stages. And through analyzing the evolution characteristics of each stage, the evolution mechanism and development trend of green building in our country are obtained.
\end{abstract}

\section{Introduction}

There are many definitions of green building, but green buildings generally are described as ones which are designed and built in consideration of the integration of environmental feedback and resource efficiency[1].At present, there are 40 billion square meters of total construction areas, and approximate $95 \%$ of them are high energy consumption buildings. And about 20 million square meters of construction area could meet the green building standards which only account for $0.05 \%$ of the total construction area [2],meaning that there is great development potentiality for green building[3].

Some scholars have conducted a more in-depth study on the game of the green building market. Such as, Anna established a non symmetric game model between the government and consumer groups[4], Pu Yunhui studied the game relationship between participants of green building public rental houses (government and tenants)[5], Wang Jinghui set up a game model among different groups of developers in the green building market[6], Zhang Yun used evolutionary game theory to analyze and study the green transformation of existing large public buildings in China[7]. However, there is no discussion on the game model for the developers and buyers.

\section{Establishing Evolution Game Model of the Green Building Market}

Evolutionary game which budding biology establishes the system model of ecological evolution to explain ecological phenomena by using pure mathematical theory[8,9], and it was completely summarized as the evolutionary game theory by Weibull in 1995[10].

In the value chain of green building, there are developers, government, potential buyers, suppliers, recycling companies and other related interest groups[11]. Among them, the developers, potential buyers and government departments are the most direct and most significant participants[12]. But in the early stage, only developers and potential buyers play a leading role, therefore, this study intends to set them as the main participants of the game.

Developers may take two types of strategies: one is to build green constructions (build green), another is to build non green constructions (build non green). Similarly, property buyers can also take two types of strategies: one is to buy green building (buy green), another is to buy non green 
building (buy non green). Utility parameters is described in table1, 2 and the payment matrix is described in table 3.

We set the proportion of developers who choose "build green" as " $x$ ", then, and set the proportion of developers who choose "build non green" as " $1-x$ ". And we set the proportion of buyers who choose "buy green" is " $y$ ", and set the proportion of buyers who choose "buy non green" as "1-y".

So, the expected benefit when developers choose to build green buildings is:

$$
U_{1}=y\left(I_{11}-C_{11}+S_{11}\right)+(1-y)\left(I_{11}-C_{11}+S_{11}-R_{11}\right)
$$

Developers' total benefit is:

$$
\bar{U}_{1}=x y\left(I_{11}-C_{11}+S_{11}\right)+x(1-y)\left(I_{11}-C_{11}+S_{11}-R_{11}\right)+(1-x) y\left(I_{12}-C_{12}-R_{12}\right)+(1-x)(1-y)\left(I_{12}-C_{12}\right)
$$

The expected benefit when buyer choose to buy green buildings is:

$$
U_{2}=x\left(I_{21}-C_{21}+S_{21}\right)+(1-x)\left(I_{21}-C_{21}+S_{21}-R_{21}\right)
$$

Buyers' total benefit is:

$$
\overline{U_{2}}=x y\left(I_{21}-C_{21}+S_{21}\right)+(1-x) y\left(I_{21}-C_{21}+S_{21}-R_{21}\right)+x(1-y)\left(I_{22}-C_{22}-R_{22}\right)+(1-x)(1-y)\left(I_{22}-C_{22}\right)
$$

Table 1 Game players' utility parameters under different strategies

\begin{tabular}{|l|c|c|c|c|}
\hline \multirow{2}{*}{} & \multicolumn{2}{|c|}{ Developers } & \multicolumn{2}{c|}{ Buyers } \\
\cline { 2 - 5 } & Build green & Build non green & Buy green & Buy non green \\
\hline Incomes (I) & $\mathrm{I}_{11}$ & $\mathrm{I}_{12}$ & $\mathrm{I}_{21}$ & $\mathrm{I}_{22}$ \\
\hline Costs (C) & $\mathrm{C}_{11}$ & $\mathrm{C}_{12}$ & $\mathrm{C}_{21}$ & $\mathrm{C}_{22}$ \\
\hline Subsidies (S) & $\mathrm{S}_{11}$ & & $\mathrm{~S}_{21}$ & \\
\hline Risks (R) & $\mathrm{R}_{11}$ & $\mathrm{R}_{12}$ & $\mathrm{R}_{21}$ & $\mathrm{R}_{22}$ \\
\hline
\end{tabular}

Table 2 Meaning of utility parameters

\begin{tabular}{|l|l|}
\hline$I_{11}$ & Developers' income when choosing green buildings \\
\hline$C_{11}$ & Developers' cost when choosing green buildings \\
\hline$I_{12}$ & Developers' income when choosing non green buildings \\
\hline$C_{12}$ & Developers' cost when choosing non green buildings \\
\hline$S_{11}$ & Subsidies from government for developers who choose green buildings \\
\hline$R_{11}$ & Risk for developers when choosing green buildings \\
\hline$R_{12}$ & Risk for developers when choosing non green buildings \\
\hline$I_{21}$ & Buyers' income when choosing green buildings \\
\hline$C_{21}$ & Buyers' cost when choosing green buildings \\
\hline$I_{22}$ & Buyers' income when choosing non green buildings \\
\hline$C_{22}$ & Buyers' cost when choosing non green buildings \\
\hline$S_{21}$ & Subsidies from government for buyers who choose green buildings \\
\hline$R_{21}$ & Risk for buyers when choosing green buildings \\
\hline$R_{22}$ & Risk for buyers when choosing non green buildings \\
\hline
\end{tabular}

Table 3 Payment matrix between buyers and developers

Buyers

Buy green $(y) \quad$ Buy non green (1-y)

Developers Build green $(\mathrm{x})$

\begin{tabular}{|l|l|}
\hline$I_{11}-C_{11}+S_{11}, I_{21}-C_{21}+S_{21}$ & $I_{11}-C_{11}+S_{11}-R_{11}, I_{22}-C_{22}-R_{22}$ \\
\hline$I_{12}-C_{12}-R_{12}, I_{21}-C_{21}+S_{21}-R_{21}$ & $I_{12}-C_{12}, I_{22}-C_{22}$ \\
\hline
\end{tabular}




\section{Solving Evolution Game Model of the Green Building Market}

On the one hand, the dynamic equations of developers who choose to construct green buildings can be described as the following equation:

$$
F_{x}=\frac{d_{x}}{d_{t}}=x\left(U_{1}-\bar{U}_{1}\right)=x(1-x)\left(I_{11}+C_{12}+S_{11}+y R_{11}+y R_{12}-I_{12}-C_{11}-R_{11}\right)
$$

(1)If $\left(I_{11}+C_{12}+S_{11}+y R_{11}+y R_{12}-I_{12}-C_{11}-R_{11}\right)=0, F_{x}$ is identical to zero, which means that all levels are stable, that is, $\mathrm{x}$ is stable.

(2)If $\left(I_{11}+C_{12}+S_{11}+y R_{11}+y R_{12}-I_{12}-C_{11}-R_{11}\right) \neq 0$,order $F_{x}=0$, then the result is $\mathrm{x}=0$ or $\mathrm{x}=1$. For developers, the final outcome of the game is that all developers would choose green buildings or non green buildings. Take the derivative of $F_{x}$ with respect to x:

$$
\frac{d_{F(x)}}{d_{x}}=(1-2 x)\left(I_{11}+C_{12}+S_{11}+y R_{11}+y R_{12}-I_{12}-C_{11}-R_{11}\right)
$$

$$
\text { Order } \frac{C_{11}+I_{12}+R_{11}-I_{11}-C_{12}-S_{11}}{R_{11}+R_{12}}=b \text {, then: }
$$

(1)When $\mathrm{y}>\mathrm{b}, \frac{d_{F(x)}}{d_{x}}\left|\mathrm{x}=1<0, \frac{d_{F(x)}}{d_{x}}\right| \mathrm{x}=0>0$, " $\mathrm{x}=1$ " is the only evolutionary stable strategy. And when the proportion of buyers who choose green buildings reach a certain point and show an upward trend,the possibility of developers who choose to build green building will increase, and ultimately green building is the best choice for developers.

(2) When $\mathrm{y}<\mathrm{b}, \frac{d_{F(x)}}{d_{x}}\left|\mathrm{x}=1>0, \frac{d_{F(x)}}{d_{x}}\right| \mathrm{x}=0<0, " \mathrm{x}=0$ " is the only evolutionary stable strategy. And when the proportion of buyers who choose green buildings cannot reach a certain point and show a downward trend, the possibility of developers to build green building will gradually decrease, and ultimately non green building is the best choice for developers. The dynamic trend is shown in Fig. 1.

On the other hand, the dynamic equations of buyers who choose to buy green buildings can be described as the following equation:

$$
F_{y}=\frac{d_{y}}{d_{t}}=y\left(U_{2}-\bar{U}_{2}\right)=y(1-y)\left(I_{21}+C_{22}+S_{21}+x R_{21}+x R_{22}-I_{22}-C_{21}-R_{22}\right)
$$

If $\left(I_{21}+C_{22}+S_{21}+x_{R_{21}}+x_{\left.R_{22}-I_{22}-C_{21}-R_{22}\right)=0,} F_{y}\right.$ is identical to zero, which means that all levels are stable, that is, $\mathrm{y}$ is stable.

(2) If $\left(I_{21}+C_{22}+S_{21}+x_{R_{21}}+x R_{22}-I_{22}-C_{21}-R_{22}\right) \neq 0$, order $F_{y}=0$, then the result is $\mathrm{y}=0$ or $\mathrm{y}=1$. For buyers, the final outcome of the game is that all buyers would choose green buildings or non green buildings. Take the derivative of $F_{y}$ with respect to y:

$$
\frac{d_{F(y)}}{d_{y}}=(1-2 y)\left(I_{21}+C_{22}+S_{21}+x R_{21}+x R_{22}-I_{22}-C_{21}-R_{21}\right)
$$

$$
\text { Order } \frac{C_{21}+I_{22}+R_{22}-I_{21}-C_{22}-S_{21}}{R_{21}+R_{22}}=a \text {, then: }
$$

(1)When $\mathrm{x}>\mathrm{a}, \frac{d_{F(y)}}{d_{y}}\left|\mathrm{y}=1<0, \quad \frac{d_{F(y)}}{d_{y}}\right| \mathrm{y}=0>0, " \mathrm{y}=1$ " is the only evolutionary stable strategy. And when the proportion of developers who choose green buildings reach a certain point and show an upward trend, the possibility of buyers who choose to buy green building will increase, and ultimately green building is the best choice for buyers.

(2) When $\mathrm{x}<\mathrm{a}, \frac{d_{F(y)}}{d_{y}}\left|\mathrm{y}=1>0, \frac{d_{F(y)}}{d_{y}}\right| \mathrm{y}=0<0, " \mathrm{y}=0 "$ is the only evolutionary stable strategy. And when the proportion of developers who choose green buildings cannot reach a certain point and show 
a downward trend, the possibility of buyers to purchase green building will gradually decrease, and ultimately non green building is the best choice for buyers. The dynamic trend is shown in Fig. 2 .

Putting Fig. 1 and Fig. 2 on the same coordinates, we can get a stable strategy analysis model which shows the changing process of evolution of dynamic. Then the model shows that the interface is divided into four regions by straight line $\mathrm{x}=\mathrm{a}, \mathrm{y}=\mathrm{b}$--I II IIIIII IV, as shown in Fig.3.

In area I, the outcome of the game is not stable; In the area II, the game results will eventually achieve to $(1,1)$; In the area III , the game results will eventually achieve to $(0,0)$; In the area IV, the outcome of the game is not stable.

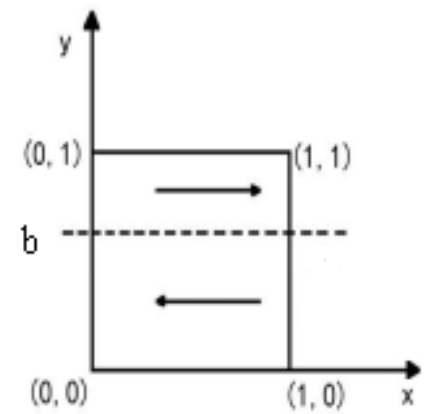

Figure 1. Developers group's dynamic trend diagram

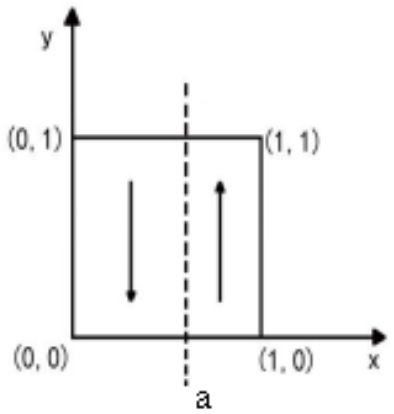

Figure 2. Buyers group's

Dynamic trend diagram

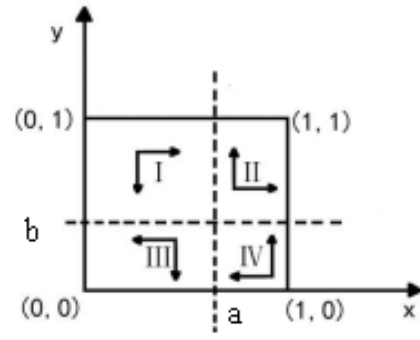

Figure 3. Dynamic and Stability trend diagram between developers and buyers

\section{Analysis on the Evolution of Green Building Market in Three Cases}

There are two assumptions in our analysis:

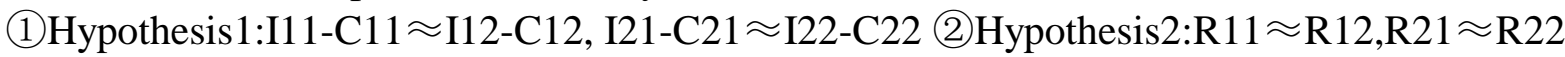

In the first case, the green building is in its initial stage where the proportion of building or purchasing green buildings is $2 \%$, the technology and market are not mature, and there is no subsidies from government for developers and consumers who choose green buildings.So, $a=\frac{R_{21}-S_{21}}{2 R_{21}}=0.5, b=\frac{R_{11}-S_{11}}{2 R_{11}}=0.5, \mathrm{x}=0.02, \mathrm{y}=0.02$. Obviously the game is in the region III and will eventually achieve to $(0,0)$ which means all developers are selected to build non green buildings and all buyers choose to buy non green buildings. In the second case, the proportion of building or purchasing green buildings reach $20 \%$, there are corresponding subsidies from government for developers who choose green buildings, and we assume that the subsidy is $\mathrm{k}$ times of the risk. So, $\quad a=\frac{R_{21}-S_{21}}{2 R_{21}}=\frac{R_{21}}{2 R_{21}}=0.5, \quad b=\frac{R_{11}-S_{11}}{2 R_{11}}=\frac{R_{11}-k R_{11}}{2 R_{11}}=0.5(1-k), \mathrm{x}=0.2, \mathrm{y}=0.2$. And if $\mathrm{k}<0.6$, the game is still in the region III and will eventually be achieve to $(0,0)$; If $\mathrm{k} \geqslant 0.6$, the game is in region I and the situation is unstable, that is if we don't want the game degenerate into $(0,0)$, we need to make sure that the subsidies are not less than 0.6 times of the risk. In the third case, the proportion of new green building will reach more than $50 \%$ and there are subsidized for the developers and buyers who choose

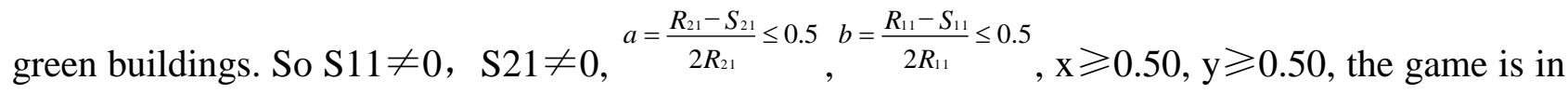
the region II and will eventually stabilize to $(1,1)$, that means all developers are selected green buildings and all buyers choose to buy green buildings. At this point, even if there is no subsidies the green building market will evolve to the situation where all developers and buyers choose green buildings. 


\section{Conclusions}

In view of the evolution of the green building market, this paper analyzes the evolutionary game theory with dynamic evolutionary thought, constructs a model of the green building market evolution, and analyzes the dynamic and incremental stability of the model.

There are four regions and two stable results. Region I means the outcome of the game is not stable; region II means the game results will eventually achieve to $(1,1)$; region III means the game results will eventually achieve to $(0,0)$; region IV means the outcome of the game is not stable. We can control these outcomes of the game by changing variable I,C,S,R and get what we want. And the this should be studied in depth in the future.

\section{References}

[1] T. Li, C.H. Liu, LEED and the structure system of "green building evaluation criteria", J. Architecture, 2011, 03:75-78.

[2] Q.K. Qian, E.H.W. Chan, L.Y.T. Choy, How transaction costs affect real estate developers entering into the building energy efficiency (BEE) market, J. Habitat International,2013(37);138-147.

[3] H. Liao, Green building subject game, market constraints and governance path, J. Green Technology, 2014, 05:269-272.

[4] Anna. Game Analysis of the economic incentive policies of the green building demand side, J. Eco Economy, 2012, 02:107-110.

[5] Y.H. Pu, Research on the main game of the standard public rental housing in the green building, J. Engineering Journal of Management， 2014， 02:112-116.

[6] J.H. Wang, X. Qin, The evolution of the green building development behavior of real estate developers, J. Building science, 2013,04:95-99.

[7] Y. Zhan, J.W. Chen, Research on the evolution of the green transformation and evolution of the large public buildings, J. Journal of Hebei University of Technology, 2015,01:113-118.

[8] V.C.Wynee-edwards, Animal Dispersion in Relation to Social Behavior, New York: Hafner, 1962.

[9] R. Robert, Dynamical System Theory in Biology, New York:Wiley-Interscience, 1970.

[10] W. Weibull, Evolutionary Game Theory, Cambridge:MIT Press .1995.

[11] S.G. Zheng, Z.W. Zhang, J.F. Zhu, Analysis of the related interest groups in the green building -Based on the green building value chain perspective, J.Technology Progress and Countermeasure, 2012,18:143-146.

[12] M.J. Zhou, On the basis of the game theory model of green building promotion system and system design, J.Green Building, 2015,03:32-37. 